\title{
How Completely and Similarly Do Safety Authorities Address Hazards Posed by New Technology? A Paradigm from Small-drone Operations
}

\author{
Anastasios Plioutsias \\ National Technical University of Athens, School of Mechanical Engineering \\ Heroon Polytechniou 9, 15780 Zografou, Athens, Greece \\ Tel: +306983505289 \\ Email: tassospl@mail.ntua.gr \\ Nektarios Karanikas \\ Amsterdam University of Applied Sciences, Faculty of Technology \\ Weesperzijde 190, Amsterdam, 1097 DZ, the Netherlands \\ Maria Mikela Chatzimichailidou, \\ University of Cambridge, Engineering Design Centre \\ Trumpington Street, Cambridge CB2 1PZ, United Kingdom
}

doi:10.5296/jss.v2i2.10442ＵRL: http://dx.doi.org/10.5296/jss.v2i2.10442

\begin{abstract}
The continuous increase of accident and incident reports has indicated the potential of drones to threaten public safety. The published regulatory framework for small drones is not visibly based on a comprehensive hazard analysis. Also, a variety in the constraints imposed by different regulatory frameworks across the globe might impede market growth and render small-drone operations even more complicated since light drones might be easily transferred and operated in various regions with diverse restrictions. In our study we applied the Systems-Theoretic Process Analysis (STPA) method to small-drone operations and we generated a first set of Safety Requirements (SR) for the authority, manufacturer, end-user and automation levels. Under the scope of this paper, we reviewed 56 drone regulations published by different authorities, and performed (1) a gap analysis against the 57 SRs derived by STPA for the authority level, and (2) Intra-Class Correlations in order to examine the extent of their harmonization. The results suggest that the regulations studied satisfy $5.3 \%$ to $66.7 \%$ of the SRs, and they are moderately similar. The harmonization is even lower when considering the range of values of various SRs addressed by the authorities. The findings from the drones' case show that regulators might not similarly and completely address hazards introduced by new technology; such a condition might affect safety and impede the distribution and use of products in the international market. A timely and harmonized standardization based on a systematic hazard analysis seems crucial for tackling the challenges stemmed from technological advancements, especially the ones available to the public.
\end{abstract}

Keywords: drones, STPA, safety requirements, safety regulations, aviation authorities, new technology. 


\section{Introduction}

Drones are air vehicles quite recently introduced, bringing a new era in aviation. Although they were first developed for military use, nowadays a wide range of users operates small drones for recreational and commercial purposes. The drone market has been rapidly growing and small-drone flights are not limited to the classic hobbyists flying radio-controlled aircraft (GrahamWild, 2016). Taking into account the rapid growth of the drone market (Business Insider, 2016), drone flights over populated areas are expected to increase exponentially in the following years. This requires an understanding of the safety risks associated with drone operations, a proactive approach and an international harmonization because although drones are flown locally, the market is global and the establishment of many different authorization systems could hinder it (GrahamWild, 2016).

The US Federal Aviation Administration (FAA) defined small Unmanned Aircraft Systems (UAS) as aircraft along with their associated elements (i.e. communication links and components required for the control of aircraft) which are required for safe and efficient operations in the National Airspace System. Despite the differences between manned and unmanned aircraft, FAA utilized a regulatory structure similar to the one used for manned aircraft, including airman certification requirements. The rule entitled "Operation and Certification of Small Unmanned Aircraft Systems" is driven mainly by two requirements; each person operating an aircraft shall (1) maintain vigilance so as to "see and avoid" other aircraft, and (2) not lose "positive control" (FAA, 2016). The former requirement asks from the end-user to monitor other airborne aircraft and avoid mid-air collisions. The latter requirement dictates that the operator shall not lose control of the drone due to failures of the link between the drone and the control station or its components. The European Aviation Safety Agency (EASA) produced a Technical Opinion including 27 topics for the development of a regulatory framework about low-risk operations of unmanned aircraft, irrespectively of their maximum certified takeoff mass (EASA, 2015). The purpose of the Technical Opinion is to foster a harmonization of regulations across the European Union (EU) countries, many of which though had already published their own rules for drone flights.

The indicative reference above to the FAA and EASA demonstrates the diversity of approaches towards drone safety. Apart from the aforementioned regions, several governmental agencies across the globe have developed their own rules and regulations $(\mathrm{R} \& \mathrm{R})$ in order to manage drone-related safety risks. A first review of those $\mathrm{R} \& \mathrm{R}$ did not provide to the authors a clear indication whether those are grounded on any risk assessment methods, and suggested that the R\&R: focus mainly on the end-user; do not consistently address small drones' design and certification; do not visibly mention own responsibilities of authorities; are more specific and strict for commercial uses of drones in comparison to recreational flights. Taking into account the aforesaid preliminary observations and the safety challenges emerging from small drone operations, in our study we derived safety requirements (SRs) based on a systemic hazard analysis and reviewed drone regulatory frameworks published by different aviation authorities in order to explore: (1) the extent to which the SRs at the authority level are satisfied by the R\&R considered, (2) which SRs are mostly and least addressed, and (3) the degree of the harmonization amongst authorities.

\section{Methodology}

In order to perform a comprehensive hazard analysis and generate respective safety requirements, the researchers applied the System Theoretic Process Analysis (STPA) method (Leveson, 2011) to a typical small-drone system. The aforementioned method was preferred over traditional hazard identification methods, such as the Fault Tree Analysis (FTA) or 
Hazard and Operability Study (HAZOP), because it suggests a systemic view and allows a more systematic approach. STPA has been successfully applied to a wide spectrum of industry cases and the elaboration on the specific method is out of the scope of this paper. However, the reader is prompted to retrieve relevant information from published research and studies.

The application of STPA led to the identification of 28 hazards and 24 contributing causal factors, leading to the formulation of 68 safety requirements distributed across the authority, manufacturer, end-user and automation levels. Only 57 of those requirements regarded the authority level and were considered in this paper (see Appendix). Space limitations do not allow the listing of the whole set of the aforementioned analysis' derivatives; those are available to the reader upon communication with the corresponding author.

Following the generation of the 57 SRs for the authority level, the authors reviewed the R\&R published by 56 aviation authorities as listed below in an alphabetical order of region and country: Africa (Botswana, South Africa), America (Argentina, Brazil, Canada, Cayman Island, Chile, Colombia, Costa Rica, Dominican Republic, Ecuador, Mexico, Panama, Peru, United States of America, Uruguay), Asia (China, Hong Kong, Indonesia, Israel, Japan, Nepal, Philippines, Saudi Arabia, Singapore, Sri Lanka, Taiwan, Thailand, Turkey, United Arabic Emirates), Europe (Austria, Belgium, Croatia, Cyprus, Denmark, Estonia, Finland, France, Germany, Greece, Hungary, Iceland, Ireland, Italy, Montenegro, Netherlands, Norway, Serbia, Slovakia, Slovenia, Spain, Sweden, Switzerland, United Kingdom) and Oceania (Australia, New Zealand). It is clarified that the regulations of Belgium and Greece were in a draft state at the time of the analysis (i.e. August 2016); under the scope of this paper, the researchers considered only the $\mathrm{R} \& \mathrm{R}$ regarding recreational uses of small drones; only $R \& R$ that were accessible online were consulted. Furthermore, it is noticed that some countries ban drone flights completely or allow drone flights after an assessment by local police and aviation authorities on a case-by-case basis; such $R \& R$ were not included in the sample.

A content analysis of each of the $56 \mathrm{R} \& \mathrm{R}$ with reference to the 57 SRs resulted to corresponding vectors with binary values: " 1 ” (i.e. the corresponding SR is satisfied) and " 0 " (i.e. the relevant SR is not satisfied). This data was used to calculate: (1) the frequencies of the SRs addressed by each authority as a means to indicate the completeness of the respective $R \& R$, (2) the frequencies of each SR satisfied across the R\&R in order to identify which SRs were least included in the R\&R, and (3) the degree of harmonization amongst the authorities. The latter was calculated in the SPSS 22 software (IBM, 2013) with the conduction of IntraClass Correlation Coefficient (ICC) statistics under the settings: Two-Way Random, Absolute Agreement, Test Value $=0$. The values of the ICC range from 0 (i.e. absolute disagreement) to 1 (i.e. absolute agreement) and a significance level of 0.05 was used for all statistical calculations. In addition to the above, the authors during the content analysis observed that although various SRs were satisfied by several R\&R in terms of description/objective, different values (e.g., minimum distance of drones from obstacles) and implementation paths (e.g., end-user's set of skills) were found. Thus, we also mapped those differences for the SRs most frequently satisfied in order to provide a more detailed picture of the diversity of approaches amongst the authorities.

\section{Results}

The gap analysis showed that the satisfaction of the 57 SRs across the 56 countries ranges from $5.3 \%$ (i.e. 3 SRs) to $66.7 \%$ (i.e. 38 SRs) with an average of 18.52 SRs satisfied (i.e. about $32 \%$ ) and a standard deviation of 8.44 SRs. For a better illustration, the distribution of 
percentages is shown in Figure 1. Due to ethical reasons, the percentages per country are not disclosed but the values can be used as an initial reference for various countries' regulators or intended future action / future work.

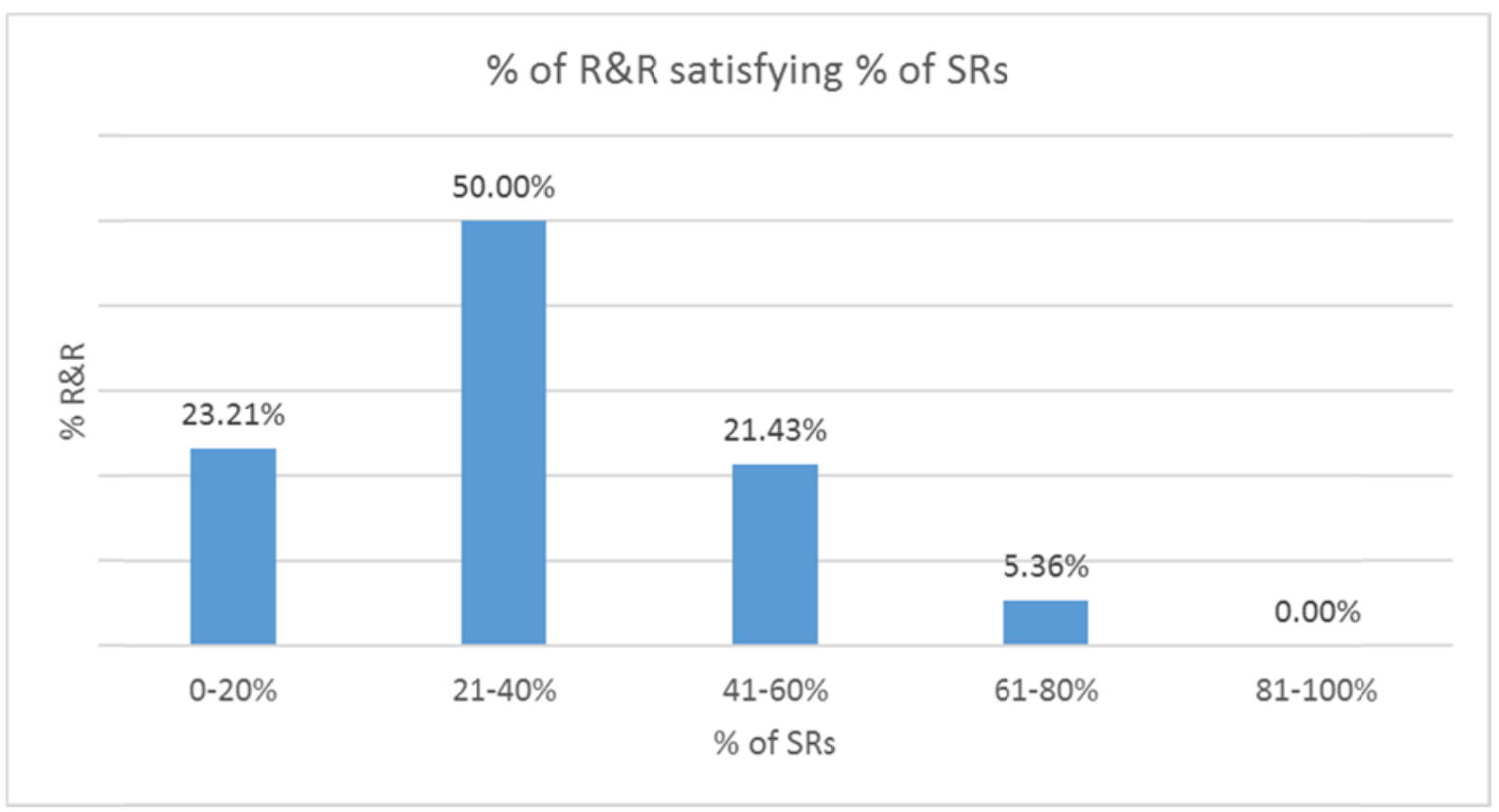

Figure 1. Distribution of the 56 R\&R satisfying the 57 SRs

The percentages of each SR's satisfaction across all R\&R are presented in the Appendix. Those percentages range from $0 \%$ for 8 SRs (i.e. no country addressed the specific SRs) to $100 \%$ for one SR (i.e. all countries satisfied the specific SR for VLOS). The SRs which no country addressed are: Drone shall be operated when designated flight area has not reached maximum drone (or other flying objects) population; Drone shall hover over landing point at TBD minimum altitude and duration; Drone shall self-land when no input received after TBD (time units) of hovering; Maintenance of drone shall be performed after fall from height at least equal to TBD (length unit); Drone shall be equipped with altitude sensors; The display characteristics related to discernment shall be adjustable; Display shall not fall in standby or sleeping mode when is required by current flight mode; Drone shall auto-hover when no command is received. Most of the aforementioned SRs are oriented to mandates of the manufacturer level.

Table 2 reports the results from the ICC tests per region. The ICC value when considering the whole sample is 0.432 , indicating a moderate similarity amongst the whole sample.

Table 2. Results from ICC statistics.

\begin{tabular}{|l|l|}
\hline Region & ICC value (i.e. degree of similarity) \\
\hline Africa & 0.391 \\
\hline America (all countries) & 0.405 \\
\hline America (North) & 0.534 \\
\hline America (Central \& South) & 0.442 \\
\hline
\end{tabular}




\begin{tabular}{|l|l|}
\hline Asia & 0.500 \\
\hline Europe & 0.436 \\
\hline Oceania & 0.506 \\
\hline
\end{tabular}

A more thorough analysis of the SRs satisfied by several countries, but referring to different values and paths for their realization, resulted to the following findings:

- Operator shall maintain continuous visual contact with drone during flight (SR 1):

In $21 \mathrm{R} \&$ Rs the values for the Visual Line of Sight (VLOS) range from $100 \mathrm{~m}$ up to $500 \mathrm{~m}$, whereas one authority requires a VLOS up to 3 nautical miles. 26 authorities don't dictate a specific VLOS range, the latter depending on the visual capability of the operator. Furthermore, in 5 countries the VLOS range depends on the flight area altitude, meteorological conditions and other environmental factors, such as the duration of the daylight. Two countries connect the VLOS range with drones' battery power and radio range.

- Skills and qualifications of the end-user (combination of SRs 4, 5, 6, 7 \& 9):

29 of the 56 authorities require from users to undertake theoretical courses and undergo skill and reevaluation tests; holders of a Private Pilot License (PPL) or higher are allowed to operate drones in 17 of those countries. 9 countries permit drones flights only in air (model) club areas and only after users are trained by certified instructors. 34 authorities require an air medical certificate and do not allow drug and alcohol consumption prior or during drone flights. Also, 44 authorities request knowledge of the native language(s) and in 32 countries the online guidance for drone users is not available in English. Apart from the countries that English is an officially spoken language, the R\&Rs of 6 countries dictate that operators shall have a command in English without though referring to a specific level of knowledge.

- Designated flight areas (combination of SRs 10 \& 11):

43 authorities define a flight altitude at least equal to the highest physical obstacle (e.g. trees, buildings, antennas) and 54 countries restrict drone flights to a maximum altitude and radius taking into account other scheduled flying activity. In 4 countries drone flights are allowed over people and buildings after end-users are granted permission by the people or owners correspondingly. Permitted flight areas or other important information for drone operators are provided by 11 authorities, which offer respective software applications. For security reasons 41 R\&Rs refer to prohibited areas for drone flights (e.g., close to government buildings, nuclear factories and military bases).

- Drone shall maintain separation of TBD (length units) from other flying objects (SR 15):

The distance from Civil and Military Air Traffic Zones (ATZ) and the boundaries of Airspace class $\mathrm{G}$ (i.e. up to $400 \mathrm{ft}$ ) is referred in $44 \mathrm{R} \& \mathrm{R}$, but the minimum distances vary from $1,5 \mathrm{Km}$ to $10 \mathrm{Km}$. 8 countries permit drones flights in higher altitudes with VLOS. In 9 countries ATZs can host drones in a case-by-case basis when positive $\mathrm{R} / \mathrm{T}$ communication is established between the drone user and the local air traffic services.

\section{Discussion}

The results regarding the percentage of SRs addressed by the regulations studied suggest that about one quarter of the authorities satisfy less than $20 \%$ of the 57 requirements generated by the STPA and only 3 countries mention $61 \%$ to $67 \%$ of those requirements. This indicates 
that the $R \& R$ in most of the countries do not sufficiently cover the whole range of the requirements that can ensure safe drone operations. When examining the SRs that are least mentioned in the regulations (i.e. less than $25 \%$ across all $R \& R$ ), it is noticed that those regard mainly to: (1) landing and hovering tasks of the operator and/or automation in cases of failures in system communications and technical problems with the drone and (2) characteristics of feedback provision to the end-user (e.g., aural and visuall messages, sensory system). Hence, the hazards stemming from the insufficient control of the drone in cases of technical failures are under addressed, and most of the R\&R do not explicitly set requirements for characteristics which enhance end-user's awareness of the system state. The latter has been acknowledged as a principal causal factor of accidents in socio-technical systems such as drones (Valavanis \& Vachtsevanos, 2014).

On one hand, the rapid expansion of drones, which might have not been fully anticipated by the authorities, and the increasing number of drone related accident and incidents perhaps drove the publication of regulations before risks were completely assessed. On the other hand, the lack of respective failure data has not yet allowed the conduction of reliability-driven risk assessments, which are principally based on probability and severity estimations. Thus, it seems that authorities have developed their drone R\&R based on experience from aircraft and flights of heavy UAS, a practice which does not account for the highly heterogeneous population of drone users. In addition, current regulations lack reference to airworthiness requirements and safety characteristics for drones and do not mention the responsibilities of authorities. Therefore, the end-user remains almost as the only responsible "system controller" who is expected to make individual risk assessments, observe rules and limits and achieve safety through proper technical maintenance and operation of drones, whereas the technical system design is does not consist part of the most R\&R.

Regarding the similarity amongst the $57 \mathrm{R} \& \mathrm{R}$, the statistical tests revealed that in overall there is a moderate harmonization across the countries, which is also visible when considering the degree of agreement per region. However, beyond the quantification of the diversity under which R\&R satisfy different SRs, the distance between the existing regulations becomes higher when considering the paths through which authorities address same requirements. The values and paths for satisfying the SRs corresponding to the VLOS maintenance, designated flight area, safe distance from other flying objects and operator's skills differ considerably across the authorities. Although the researchers focused on the SRs that were most frequently mentioned in the R\&R studied, a similar diversitty was observed for the rest of the requirements.

To the knowledge of the authors, the realization of EASA's concept for the development of customized national R\&Rs proceeds slowly. In this phase, many European countries have already published their R\&Rs, which must be synchronized with EASA requirements in the future. The high differentiation of rules across countries, regardless of the continent and region, might confuse users and affect the market. Today, anyone can purchase a small drone regardless of age, technical and maintenance skills and abilities, familiarity with flights and cultural background. The lack of homogeneity across end-users is a challenge and a potential threat for authorities, whose R\&R, however, on one hand emphasize on the safety obligations of drone operators and, on the other hand, do not introduce proactive feedback mechanisms to inform authorities about the exertion of end-users' safety responsibilities. Furthermore, the easy transportation of small drones across countries render the aforementioned challenges even higher. This reality has led to reactive approaches such as drone jamming and capture of drones with nets, hawks and airborne robots. 
Various governmental authorities have tried to control proactively some of the aforementioned problems by requiring training of drone users in aviation fundamentals, a practice that is expected to increase the cost of using drones due to respective fees, and might discourage end users who are reluctant on investing a lot of time in lessons. Those factors may impede market growth and could not suffice alone to face the emerging safety issues with drone flights. The authors do not suggest that respective training is not worth; instead, we envisage that authorities can adopt a customizable and flexible regulatory framework, which will:

- Classify drones depending on how risk control is distributed between the operator and the automated functions of drones.

- Based on the classification above, define the set and boundary values for certification, training, maintenance etc. requirements.

\section{Conclusion.}

The application of the STPA method allowed the researchers to: (1) systematically derive safety requirements for various system controllers without the use of reliability data, (2) develop vectors used in the comparison of various "systems" and (3) perform simple statistical tests for quantifying the respective differences. The analysis of 56 regulations about recreational uses of drones showed that the formers meet the requirements of the authority level at low to average levels and are moderately similar to each other. Further qualitative analysis revealed differences in the way SRs are operationalized by the authorities, indicating an even lower degree of harmonization amongst countries and regions.

A common international regulatory framework based on a systemic and systematic risk analysis is needed to face current safety challenges and, at the same time, avoid an impediment of drone market's growth. Such a framework must clearly state the roles, responsibilities and interdependencies of the main system controllers, namely authorities, manufacturers, end-users and automation. The requirements derived by the STPA in the frame of this study might be rectified based on the experience and knowledge of the industry and serve as a first reference for developing common standards across countries.

The paradigm from small-drones indicates that safety authorities might not similarly and completely address hazards introduced by new technology, a condition indicating a discrepancy that can affect the distribution and use of products in the international market. Regardless of the type of new technology, timely standardization of safety requirements based on a systematic hazard analysis seems to be crucial for ensuring the maintenance of safety levels and avoiding manufacturing, production and modification costs, possibly stemming from delayed requirements, which are usually published as a result of accidents and incidents. The current approach by regulators is a "reactive" control (lagging) approach and the use of STPA enables a very valuable "pro-active" control (leading) approach to the risks presented by small drone operations, which is expected to reduce the number of incidents and accidents that will inevitably occur.

\section{References}

Andrea, D. (2014). Can drones deliver? IEEE Transportation Automated. 11, pp. 647-648. Science Engineering.

Bartsch, R. (2015). Unmanned and uncontrolled: The commungling theory and the lagality of unmanned aircraft system operations. Aeronaut. Aerospace Eng. (4), 104.

Bors cova, D. D. (2014). Utilization possibilities of unmanned aerial systems in postal and 
parcel services. Acta Avion, 2, p. 16.

Business Insider. (2016, JULY 10). THE DRONES REPORT: Market forecasts, regulatory barriers, top vendors, and leading commercial applications. Retrieved AUGUST 30, 2016 from business insider: THE DRONES REPORT: Market forecasts, regulatory barriers, top vendors, and leading commercial applications

EASA. (2015). Introduction of a regulatory framework for the operation of unmanned aircraft. Cologne, ermany: European Aviation Safety Agency.

English, B., Kraus, J., \& Pillar, P. (13-16 October 2014). Using unmanned aerial systems for aircraft accident investigations. Adelaide, Australia: ISASI.

European RPAS Steering Group. (n.d.). . Roadmap for the Integration of Civil RemotelyPiloted Aircraft Systems into the European Aviation System: Annex 1. Retrieved July 28, 2016 from http://ec.europa.eu/enterprise/sectors/ aerospace/files/rpas-roadmap-annex-1_en.pdf

FAA. (n.d.). Integration of civil unmanned Aircraf System (UAS) in the National Airspace System (NAS). $\quad$ Retrieved August 2, 2016 from https://www.faa.gov/uas/media/UAS_Roadmap_2013.pdf

FAA. (2016, August 29). New FAA Rules for Small Unmanned Aircraft Systems Go Into Effect. Retrieved August 30, 2016 from Press Release: http://www.faa.gov/news/press_releases/news_story.cfm?newsId=20734

GrahamWild, J. M. (2016). Exploring Civil Drone Accidents and Incidents to Help Prevent Potential Air Disasters. Aerospace .

IBM. (2013). IBM SPSS Statistics for Windows, VERSION 22.0. Armonk, NY, USA.

ICAO. (2015). Manual On Remotely Piloted Aircraft Systems, (1st ed., Vol. 10019). Monteral, QC, Canada: ICAO.

Leveson, N. (2011). Engineering a safer world: Systems thinking applied to safety. Boston: MIT Press.

Valavanis, K., \& Vachtsevanos, G. (2014). Handbook of Unmanned Aerial Vehicle. Dordrecht, Netherlands: Springer.

Radiant Insights I. Commercial drones: Highways in the sky, commercial unmanned aerial systems (UAS), market shares, strategies, and forecasts, worldwide, 2015-2021. http://www.radiantinsights.com/research/commercial-drones-highways-in-the-skycommercial-unmanned-aerial-systems-uas-market. Published January 8, 2015. Accessed September 14, 2016.

Intelligence. THE DRONES REPORT: Market forecasts, regulatory barriers, top vendors, and leading commercial applications. Business Insider. http://uk.businessinsider.com/uav-orcommercial-drone-market-forecast-2015-27r=US\&IR=T. Published June 10, 2016. Accessed July 2, 2016.

Campion-Smith B, Ottawa Bureau. Drone close calls near airports spur proposed regulations | Toronto star. Canada. https://www.thestar.com/news/canada/2016/06/11/drone-close-callsnear-airports-spur-proposed-regulations.html. Published June 11, 2016. Accessed July 10, 2016.

Vanian J. More drones are flying too close to comfort to airplanes and airports. Tech. http://fortune.com/2016/03/28/drones-flying-too-close-airplanes-airports/. Published March 28, 2016. Accessed September 10, 2016. 


\section{Macrothink}

EASA. Annual Safety Report 2016. Brussels: European Aviation Safety Agency, 2016.

\section{Glossary}

ATZ: Air Traffic Zone

EASA: European Aviation Safety Agency

EU: European Union

FAA: Federal Aviation Administration

FTA: Fault Tree Analysis

HAZOP: Hazard and Operability

ICC: Intra-Class Correlation Coefficient

PPL: Private Pilot License

R\&R: Rules and Regulations

STPA: Systems-Theoretic Process Analysis

SR(s): Safety Requirement(s)

UAS: Unmanned Aircraft Systems

VLOS: Visual Line of Sight

\section{Appendix}

Safety Requirements (SRs) generated with STPA

\begin{tabular}{|c|c|c|c|}
\hline \multirow[t]{2}{*}{ No } & \multirow[t]{2}{*}{ REQUIREMENTS AT THE AUTHORITY LEVEL } & \multicolumn{2}{|c|}{$\begin{array}{l}\text { Countries including the } \\
\text { requirement in their } \\
\text { R\&R }\end{array}$} \\
\hline & & Frequency & $\%$ \\
\hline 1 & $\begin{array}{l}\text { Operator shall maintain continuous visual contact with } \\
\text { drone during flight }\end{array}$ & 56 & 100.0 \\
\hline 2 & $\begin{array}{l}\text { Define health related instructions (e.g., leakages, radiation, } \\
\text { body contact with moving surfaces) }\end{array}$ & 43 & 76.8 \\
\hline 3 & $\begin{array}{l}\text { Specific set of safety constraints shall be maintained by } \\
\text { automation during drone operation }\end{array}$ & 17 & 30.4 \\
\hline 4 & Operator shall meet technical competencies & 29 & 51.8 \\
\hline 5 & $\begin{array}{l}\text { Operator shall accomplish familiarization stages for drone } \\
\text { operation }\end{array}$ & 29 & 51.8 \\
\hline 6 & Operator shall be physically fit to operate the drone & 34 & 60.7 \\
\hline 7 & $\begin{array}{l}\text { Operator shall command English at TBD level when in } \\
\text { country where operator's native language is not the official } \\
\text { one }\end{array}$ & 12 & 21.4 \\
\hline
\end{tabular}




\begin{tabular}{|c|c|c|c|}
\hline \multirow[t]{2}{*}{ No } & \multirow[t]{2}{*}{ REQUIREMENTS AT THE AUTHORITY LEVEL } & \multicolumn{2}{|c|}{$\begin{array}{l}\text { Countries including the } \\
\text { requirement in their } \\
\mathbf{R} \& \mathbf{R}\end{array}$} \\
\hline & & Frequency & $\%$ \\
\hline 8 & $\begin{array}{l}\text { Agencies supporting drone flights shall offer to operators } \\
\text { communication in English }\end{array}$ & 31 & 55.4 \\
\hline 9 & $\begin{array}{l}\text { Operator shall meet cognitive requirements for drone } \\
\text { control }\end{array}$ & 26 & 46.4 \\
\hline 10 & $\begin{array}{l}\text { Drone shall be operated in designated flight areas, where a } \\
\text { minimum altitude at least equal to the highest physical } \\
\text { obstacle shall be defined }\end{array}$ & 43 & 76.8 \\
\hline 11 & $\begin{array}{l}\text { Drone shall be operated in flight areas designated taking } \\
\text { into account other scheduled flying activity (maximum } \\
\text { altitude and radius) }\end{array}$ & 54 & 96.4 \\
\hline 12 & $\begin{array}{l}\text { Drone shall be operated in flight areas designated taking } \\
\text { into account effects of electromagnetic fields }\end{array}$ & 42 & 75.0 \\
\hline 13 & Designated flight areas shall be periodically reassessed & 33 & 58.9 \\
\hline 14 & $\begin{array}{l}\text { Drone shall be maintained at the minimum altitude TBD of } \\
\text { the designated area before landing, so to be noticed, and } \\
\text { after takeoff so to complete the process of auto initial } \\
\text { alignment }\end{array}$ & 1 & 1.8 \\
\hline 15 & $\begin{array}{l}\text { Drone shall maintain separation of TBD (length units) from } \\
\text { other flying objects }\end{array}$ & 41 & 73.2 \\
\hline 16 & $\begin{array}{l}\text { Drone shall be operated when designated flight area has not } \\
\text { reached maximum drone (or other flying objects) } \\
\text { population }\end{array}$ & 0 & 0.0 \\
\hline 17 & $\begin{array}{l}\text { Drone shall be operated at frequency range of designated } \\
\text { flight area }\end{array}$ & 5 & 8.9 \\
\hline 18 & Drone shall be operated only when weather minima are met & 43 & 76.8 \\
\hline 19 & $\begin{array}{l}\text { Operator shall consult weather forecasting every TBD (time } \\
\text { units) }\end{array}$ & 21 & 37.5 \\
\hline 20 & $\begin{array}{l}\text { Information about drone technical condition when activated } \\
\text { shall be provided to the operator }\end{array}$ & 20 & 35.7 \\
\hline 21 & Drone shall meet reliability requirements & 35 & 62.5 \\
\hline 22 & $\begin{array}{l}\text { Drone subsystems allowing full control in manual mode } \\
\text { shall be operative before takeoff }\end{array}$ & 22 & 39.3 \\
\hline 23 & $\begin{array}{l}\text { Communication amongst drone subsystems required for at } \\
\text { least manual flight shall be established before takeoff }\end{array}$ & 17 & 30.4 \\
\hline
\end{tabular}




\begin{tabular}{|c|c|c|c|}
\hline \multirow[t]{2}{*}{ No } & \multirow[t]{2}{*}{ REQUIREMENTS AT THE AUTHORITY LEVEL } & \multicolumn{2}{|c|}{$\begin{array}{l}\text { Countries including the } \\
\text { requirement in their } \\
\text { R\&R }\end{array}$} \\
\hline & & Frequency & $\%$ \\
\hline 24 & $\begin{array}{l}\text { Drone shall be landed when any subsystem/component not } \\
\text { operative more than TBD (time unit) and drone's full } \\
\text { control in manual mode is not possible }\end{array}$ & 5 & 8.9 \\
\hline 25 & $\begin{array}{l}\text { Drone shall be landed when communication between any } \\
\text { subsystem/component lost more than TBD (time unit) }\end{array}$ & 3 & 5.4 \\
\hline 26 & $\begin{array}{l}\text { Drone shall be landed when any failure of automation } \\
\text { cannot be compensated by manual control }\end{array}$ & 19 & 33.9 \\
\hline 27 & $\begin{array}{l}\text { Drone shall be landed when any communication problem } \\
\text { occurred more than TBD times during flight }\end{array}$ & 2 & 3.6 \\
\hline 28 & $\begin{array}{l}\text { Drone shall hover over landing point at TBD minimum } \\
\text { altitude and duration }\end{array}$ & 0 & 0.0 \\
\hline 29 & $\begin{array}{l}\text { Aural notifications shall be provided when drone lower than } \\
\text { minimum allowed altitude }\end{array}$ & 1 & 1.8 \\
\hline 30 & $\begin{array}{l}\text { Visual notifications shall be provided when drone lower } \\
\text { than minimum allowed altitude }\end{array}$ & 3 & 5.4 \\
\hline 31 & $\begin{array}{l}\text { Drone shall be landed when environmental conditions into } \\
\text { which drone maintains designed reliability are not met }\end{array}$ & 49 & 87.5 \\
\hline 32 & $\begin{array}{l}\text { Environmental conditions into which drone maintains } \\
\text { designed reliability shall be met before takeoff }\end{array}$ & 47 & 83.9 \\
\hline 33 & Display shall provide information for drone operating mode & 8 & 14.3 \\
\hline 34 & Display shall provide information for position & 16 & 28.6 \\
\hline 35 & $\begin{array}{l}\text { Display shall provide information for auto-functions' (de) } \\
\text { activation }\end{array}$ & 3 & 5.4 \\
\hline 36 & Display shall provide information for power level & 6 & 10.7 \\
\hline 37 & Display shall provide information for malfunctions & 17 & 30.4 \\
\hline 38 & $\begin{array}{l}\text { Display shall provide information for proximity to range } \\
\text { area }\end{array}$ & 16 & 28.6 \\
\hline 39 & $\begin{array}{l}\text { Drone shall be landed when any drone's movement in space } \\
\text { not a result of command input }\end{array}$ & 2 & 3.6 \\
\hline 40 & $\begin{array}{l}\text { Drone shall self-land when no input received after TBD } \\
\text { (time units) of hovering }\end{array}$ & 0 & 0.0 \\
\hline 41 & $\begin{array}{l}\text { Drone shall be landed when level of power drops under } \\
\text { TBD (power unit) }\end{array}$ & 2 & 3.6 \\
\hline
\end{tabular}




\begin{tabular}{|l|l|l|l|}
\hline No & REQUIREMENTS AT THE AUTHORITY LEVEL & \multicolumn{2}{l|}{$\begin{array}{l}\text { Countries including the } \\
\text { requirement in their } \\
\text { R\&R }\end{array}$} \\
\cline { 3 - 5 } & \multicolumn{2}{|l|}{ Frequency } & $\%$ \\
\hline $\mathbf{4 2}$ & $\begin{array}{l}\text { Maintenance of drone shall be performed after fall from } \\
\text { height at least equal to TBD (length unit) }\end{array}$ & 0 & 0.0 \\
\hline $\mathbf{4 3}$ & Drone shall be equipped with altitude sensors & 0 & 0.0 \\
\hline $\mathbf{4 4}$ & Drone shall be subject to periodic maintenance & 38 & 67.9 \\
\hline $\mathbf{4 5}$ & Drone shall be subject to on-condition maintenance & 35 & 62.5 \\
\hline $\mathbf{4 6}$ & $\begin{array}{l}\text { Generate aural warning shall be provide when failure is } \\
\text { detected }\end{array}$ & 2 & 3.6 \\
\hline $\mathbf{4 7}$ & $\begin{array}{l}\text { Generate aural warning shall be provided when drone } \\
\text { reaches or violates range limits }\end{array}$ & 1 & 1.8 \\
\hline $\mathbf{4 8}$ & $\begin{array}{l}\text { UAS documentation shall include manual and automated } \\
\text { functions, and technical specifications }\end{array}$ & 45 & 80.4 \\
\hline $\mathbf{4 9}$ & Operator shall observe limitations of display view & 2 & 3.6 \\
\hline $\mathbf{5 0}$ & Operator shall use drone documentation in native language & 34 & 60.7 \\
\hline $\mathbf{5 1}$ & $\begin{array}{l}\text { Manufacturer shall provide drone documentation in official } \\
\text { language(s) of targeted market }\end{array}$ & 9 & 16.1 \\
\hline $\mathbf{5 2}$ & $\begin{array}{l}\text { The display characteristics related to discernment shall be } \\
\text { adjustable }\end{array}$ & 0 & 0.0 \\
\hline $\mathbf{5 3}$ & $\begin{array}{l}\text { Display shall not fall in standby or sleeping mode when is } \\
\text { required by current flight mode }\end{array}$ & 0 & 0.0 \\
\hline $\mathbf{5 4}$ & Messages shall be displayed in native language & 14 & 25.0 \\
\hline $\mathbf{5 5}$ & $\begin{array}{l}\text { Prioritization actions, alerts and messages shall be provided } \\
\text { to facilitate operator's reaction under emergency }\end{array}$ & 1 & 0.0 \\
\hline $\mathbf{5 6}$ & Operator should not be under high emotional state & 3 & 5.4 \\
\hline $\mathbf{5 7}$ & Drone shall auto-hover when no command is received & 0 & 0.0 \\
\hline
\end{tabular}

\section{Copyright Disclaimer}

Copyright for this article is retained by the author(s), with first publication rights granted to the journal.

This is an open-access article distributed under the terms and conditions of the Creative

Commons Attribution license (http://creativecommons.org/licenses/by/3.0/) 